\title{
Neural Networks Based Power Flow Control of the Doubly Fed Induction Generator
}

\author{
Orlando Soares ${ }^{1}$, Henrique Gonçalves ${ }^{2}$, António Martins ${ }^{3}$ and Adriano Carvalho ${ }^{4}$ \\ ${ }^{1}$ University of Applied Sciences of Bragança \\ Campus de Santa Apolónia, 5301-857 Bragança, Portugal \\ Phone/Fax number: + 351273313050/51 \\ ${ }^{2,3,4}$ Faculty of Engineering of the University of Porto \\ Rua Dr. Roberto Frias, 4200-465 Porto, Portugal \\ Phone/Fax number: $+351225081442 / 893$ \\ 1 osoares@ipb.pt, ${ }^{2}$ hengo@fe.up.pt, ${ }^{3}$ ajm@fe.up.pt and ${ }^{4}$ asc@fe.up.pt
}

\begin{abstract}
This paper describes the models of wind power system, such as the turbine, the generator, the power electronics converters and the controllers, with the aim to control the generation of wind power in order to maximize the power generated with the lowest possible impact in the voltage and the frequency of the grid during normal operation and under the occurrence of faults. The present work considers a wind power system equipped with the Doubly Fed Induction Generator (DFIG) and a converter connected between the rotor and the grid. This system allows independent control of active and reactive power using neural networks based controllers.
\end{abstract}

\section{INTRODUCTION}

The aim of the control system of a wind turbine is to obtain a secure and automatic operation of the turbine using an optimized flow of the generated power. This will reduce operation costs, producing a consistent dynamic response and improving the quality of power. Also, it helps in the assurance of the safety for the maximization of the energy captured due to the decrease of the turbine load.

The present development in the wind power domain production is strong on the development of methods and technologies capable of providing the production of energy based in systems using the asynchronous induction generator. This development is only possible with the association of the electric machine with power electronics converters capable of imposing to this type of machine conditions of variable speed for the actual unit power levels of produced energy [1].

In this scene of integrated production, based in variable speed asynchronous machines, there are needed methods capable of controlling the system imposing an optimal power flow in the electric machine according to certain conditions of the rotor speed, [2]-[4].

The application of artificial intelligence techniques in the fields of the power electronics and control systems has been growing. These techniques, based on intelligent systems such as fuzzy logic and neural networks (NN), need a large database and knowledge that together will describe the functioning with a logical analysis, instead of a mathematical analysis to control systems and to make possible the taking of decisions. Actually, NNs tend to be applied in the field of power electronics and control systems. This tendency takes us to substitute some parts of the common vector control systems by a NN based control system [5].

In this research work it is presented an application of NNs in vector control systems for a DFIG used in a wind power system. This technology, relatively new in this type of application, will be used to efficiently substitute conventional controllers.

For the vector control system it is used a feed forward back propagation neural network [6] in order to substitute some parts of the vector control system. They are used to estimate and provide the reference currents to control the system variables. Each neural network is designed, trained and tested as a part of the control system with the aim of optimization the production of energy, having in account the quality of the power delivered to the electric grid.

It is shown that the feed forward back propagation NN type can be used to generate the reference control voltages for the rotor-side and grid-side converters, decoupling the machine active and reactive powers.

Thus, an interactive approach is made supported in an integrated model developed in the Matlab/Simulink environment in order to complete the study of the wind power production system.

It is verified that the use of control techniques with NNs has not been widely used in this field. Reference [7] presents a control system based on NNs to generate a value for the aerodynamic power coefficient, $C_{p}$. A similar work was presented in [8]. It is in this context that this work gives its contribution, presenting a control strategy using $\mathrm{NNs}$ to generate the reference parameters to control the generator: the operating point changes during the normal functioning or, in the case of using turbines of variable speed or in situation of fault occurrence, PI controllers can't supply an enough damping or an acceptable performance. To avoid this drawback voltage and power regulators based on NNs are introduced, since neural networks offer more advantages than 
non-linear adaptive controllers in terms of robustness, performance, learning capability and greater flexibility. Thus, it is demonstrate that NNs can be implemented and used in the control of real time wind energy conversion systems. Behalf that, the implemented system revealed to be more robust and with a superior performance than systems that use traditional control methods like PI ones.

\section{SySTEM MODELS}

\section{A. Turbine and Drive-train}

For the determination of the aerodynamic power and torque $C_{P}(\lambda, \beta)$ curves for each turbine are used. Each curve can be understood as a set of the turbine $C_{P}(\lambda)$ curve for different values of the pitch angle $\beta$. Each operation point $C_{P}(\lambda)$ with a particular $\beta$ represents one situation of equilibrium. Thus, the representation of the $C_{P}(\lambda, \beta)$ curves is used considering that the turbine is in equilibrium in each point of its operation. In those conditions, the aerodynamic power is given by the following expression [9]:

$$
P_{a e}=\frac{1}{2} \rho \pi R^{2} v^{3} C_{P}(\lambda, \beta)
$$

with $R$ being the radius of the turbine and $v$ the wind speed.

The drive-train mechanical model is described by its spacestate equations [10]:

$$
\begin{gathered}
\overline{\dot{x}}=\left[\begin{array}{ccc}
0 & 0 & 1 \\
0 & 0 & 1 \\
-\frac{k_{v}}{J_{T}} & 0 & -\frac{c_{v}}{J_{T}}
\end{array}\right] \bar{x}+\left[\begin{array}{cc}
\frac{1}{\eta} & 0 \\
0 & 0 \\
\frac{c_{s}}{\eta J_{T}} & \frac{1}{J_{T}}
\end{array}\right] \bar{u} \\
\bar{y}=\left[\begin{array}{ccc}
\frac{k_{v}}{\eta} & 0 & \frac{c_{v}}{\eta} \\
0 & 1 & 0 \\
0 & 0 & 1
\end{array}\right] \bar{x}+\left[\begin{array}{cc}
-\frac{c_{v}}{\eta^{2}} & 0 \\
0 & 0 \\
0 & 0
\end{array}\right] \bar{u}
\end{gathered}
$$

with the input variable $\bar{u}=\left[\begin{array}{ll}\omega_{r} & T_{m}\end{array}\right]^{T}$, output variables $\bar{y}=\left[\begin{array}{lll}T_{a v v} & \theta_{m} & \omega_{m}\end{array}\right]^{T}$ and state variables $\bar{x}=\left[\begin{array}{lll}\theta_{k} & \theta_{m} & \omega_{m}\end{array}\right]^{T}$.

\section{B. Doubly Fed Induction Generator}

The model of the asynchronous machine uses the Park equations [11], expressing the variables in the $d q$ reference system, rotating with the speed of the stator voltage (synchronous frame). An approach of the coupling circuit and the notation of the machine used is the same used by Ong [12]. The voltage equations of the stator circuit and of the rotor can be written of the following form:

$$
\begin{gathered}
\left\{\begin{array}{l}
v_{q s}=r_{s} i_{q s}+\omega \lambda_{d s}+\frac{d \lambda_{q s}}{d t} \\
v_{d s}=r_{s} i_{d s}-\omega \lambda_{q s}+\frac{d \lambda_{d s}}{d t} \\
v_{0 s}=r_{s} i_{0 s}+\frac{d \lambda_{0 s}}{d t}
\end{array}\right. \\
\left\{\begin{array}{l}
v_{q r}^{\prime}=r_{r}^{\prime} i_{q r}^{\prime}+\left(\omega-\omega_{r}\right) \lambda_{d r}^{\prime}+\frac{d \lambda_{q r}^{\prime}}{d t} \\
v_{d r}^{\prime}=r_{r}^{\prime} i_{d r}^{\prime}-\left(\omega-\omega_{r}\right) \lambda_{q r}^{\prime}+\frac{d \lambda_{d r}^{\prime}}{d t} \\
v_{0 r}^{\prime}=r_{r}^{\prime} i_{0 r}^{\prime}+\frac{d \lambda_{0 r}^{\prime}}{d t}
\end{array}\right.
\end{gathered}
$$

The developed torque is given by:

$$
T_{e m}=\frac{3}{2} \frac{p}{2}\left(\lambda_{q r}^{\prime} i_{d r}^{\prime}-\lambda_{d r}^{\prime} i_{q r}^{\prime}\right) \approx \frac{3}{2} \frac{p}{2} L_{m}\left(i_{d r}^{\prime} i_{q s}-i_{q r}^{\prime} i_{d s}\right)
$$

The rotor rotating movement equation is obtained equating the accelerating torque to the inertia torque and friction:

$$
T_{e}-T_{m}=J_{G} \frac{d \omega_{r}}{d t}+D \omega_{r}
$$

\section{Back-to-Back Converter}

The model used for the converters is show in Fig. 1 and uses the average converer model in the $q d$ reference frame [13].

The grid angular position $\theta=\omega t$ is obtained by means of the use of a Phase Locked Loop (PLL) available in the Matlab/Simulink Toolbox. The operation of the grid-side converter is described by the equations:

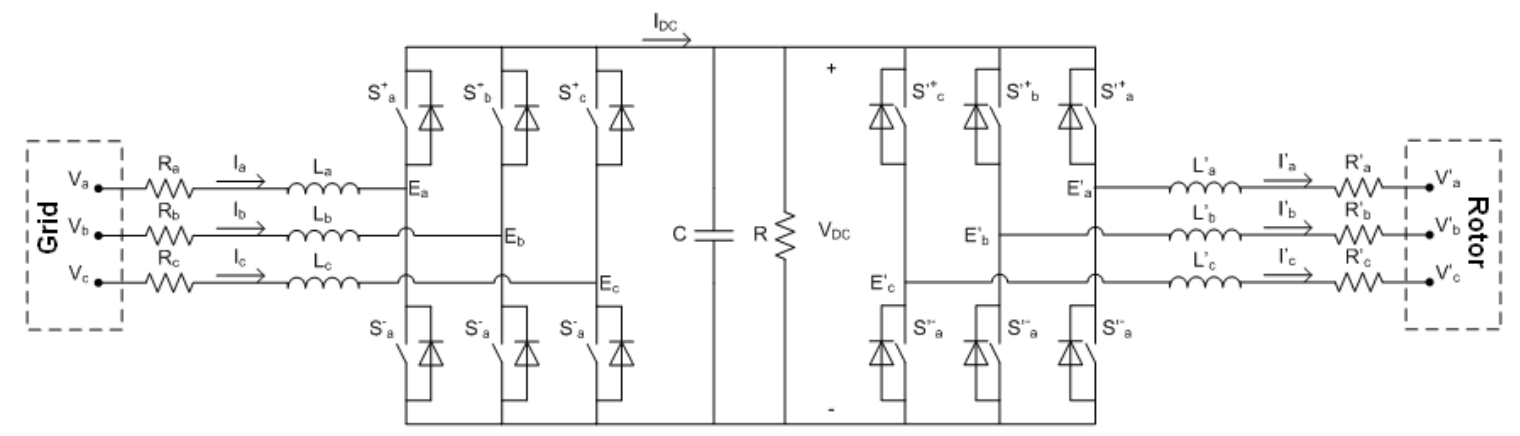

Fig.1. Back-to-back converter for the grid connection of the DFIG. 


$$
\begin{gathered}
\frac{d}{d t}\left[\begin{array}{l}
I_{d} \\
I_{q}
\end{array}\right]=\frac{1}{L_{a}}\left[\begin{array}{l}
V_{d} \\
V_{q}
\end{array}\right]+\left[\begin{array}{rr}
-\frac{R_{a}}{L_{a}} & \omega \\
-\omega & -\frac{R_{a}}{L_{a}}
\end{array}\right]\left[\begin{array}{l}
I_{d} \\
I_{q}
\end{array}\right]-\frac{1}{L_{a}}\left[\begin{array}{l}
d_{d} \\
d_{q}
\end{array}\right] V_{D C} \\
\frac{d V_{D C}}{d t}=\frac{1}{C}\left[\begin{array}{ll}
d_{d} & d_{q}
\end{array}\right]\left[\begin{array}{l}
I_{d} \\
I_{q}
\end{array}\right]-\frac{V_{D C}}{R C}
\end{gathered}
$$

being the $d_{d}$ and $d_{q}$ the converter duty cycles and $R$ the resistance equivalent to the power flow in the DC bus.

The operation of the rotor-side converter is described similarly as the previous converter.

$$
\frac{d}{d t}\left[\begin{array}{l}
I_{d}^{\prime} \\
I_{q}^{\prime}
\end{array}\right]=-\frac{1}{L_{a}^{\prime}}\left[\begin{array}{l}
V_{d}^{\prime} \\
V_{q}^{\prime}
\end{array}\right]+\left[\begin{array}{cc}
-\frac{R_{a}^{\prime}}{L_{a}^{\prime}} & -\omega \\
\omega & -\frac{R_{a}^{\prime}}{L_{a}^{\prime}}
\end{array}\right]\left[\begin{array}{l}
I_{d}^{\prime} \\
I_{q}^{\prime}
\end{array}\right]+\frac{1}{L_{a}^{\prime}}\left[\begin{array}{l}
d_{d}^{\prime} \\
d_{q}^{\prime}
\end{array}\right] V_{D C}
$$

\section{Control Strategies}

Generally, the main goals of the control strategies for wind turbines are [14]:

1. to maximize the production of energy;

2. to guarantee a secure functioning of the turbine;

3. to minimize the operation and maintenance costs through the load reduction and increase of the life time use.

It is intended to control the power delivered by each generator in a way to optimize the operation of the wind park with propose to deliver the maximum active power to the grid in conditions of quality of service and safety. Also it intends to control the reactive power flow according to specified needs and due to the limitation of normative laws and dispatch.

Thus, an adequate control strategy cans [15]:

- control the active power supplied by the turbine in order to optimize the operating point;

- limit the active power in the case of high wind speed;

- control the reactive power interchange between the generator and the grid, especially in the case of weak grids, where voltage fluctuations can occur;

- guarantee the quality of service of the wind park, namely the grid voltage;

- minimize the wind park exploration and maintenance costs.

The conversion system contains two control modules, one for the rotor-side and another for the grid-side converter. The aim of the rotor-side converter is the independent control of the active power and reactive power which are controlled, not directly, but through the control of the rotor current. The aim of the grid-side converter is to keep the DC voltage constant in the intermediate capacitor in order to guarantee an operation of the converter with unity power factor, guaranteeing only the exchange of reactive power through the stator. The rotor-side converterr is controlled from the diagram presented in Fig. 2, [16].
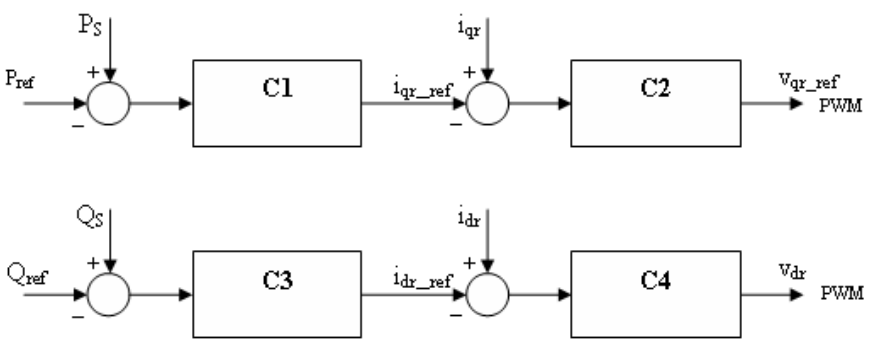

Fig. 2. Generic control block diagram for the rotor-side converter.

In Fig. 2, $P_{S}$ is the active power and $Q_{S}$ is the reactive power measured in the stator of the generator, $P_{r e f}$ is the reference value for the active power and is obtained from the turbine characteristic for the actual rotor speed and pitch angle. The value of $Q_{r e f}$ is defined in a way to keep constant the voltage at the grid connection.

\section{CONTROL SYSTEM USING NNS}

\section{A. Introduction}

The control system uses NNs to substitute some blocks of the system of traditional vector control with PI controllers [16]. These NNs was developed in the Matlab/Simulink environment and will allow to present comparisons between the traditional systems with PI controllers and the NNs systems. Thus, it is intended to present a controller based on neural networks to be used in the control system alternatively to the ones based on PI controllers.

The NNs are used with the intention of efficiently extracting the wind energy; this is, to be able to extract the maximum power of the turbine during some situations of functioning through the estimation of the two converters control parameters.

\section{B. NNs Controllers Architecture}

For the rotor-side controller was used a 7-15-10-2 neural network configuration as is shown in Table I, where the inputs are the stator and rotor currents, the rotor-side reference currents and the rotor angular speed, and the outputs are the reference voltages to control the rotor-side converter.

For the grid-side controller was used a 7-18-8-2 neural network configuration as is shown in Table II, where the inputs are the stator currents, the grid-side reference currents, and the angular frequency $\omega_{s}$, and the outputs are the reference voltages to control the grid-side converter.

In the $\mathrm{NN}$ training, the learning algorithm [17] actualizes the values of the weights and bios values according to the descendent gradient with momentum factor and adaptive learning ratio, also indicated in the table. The sampling frequency is of $20 \mathrm{kHz}$. The numbers of time delays used in each layer of the neural networks has been adjusted as a result of several simulations.

The used learning input-output pairs were generated by several system simulations and contemplate points with the machine operating in three zones: below, near and above the synchronism speed. 
TABLE I

ROTOR-SIDE CONTROLLER NEURAL NETWORK ARCHITECTURE

\begin{tabular}{|l|c|c|c|}
\hline & $\begin{array}{c}\text { 1st Hidden } \\
\text { Layer }\end{array}$ & $\begin{array}{c}\text { 2nd Hidden } \\
\text { Layer }\end{array}$ & $\begin{array}{c}\text { Output } \\
\text { Layer }\end{array}$ \\
\hline No of inputs & \multicolumn{3}{|c|}{7 inputs } \\
\hline No of neurons & 15 & 10 & 2 \\
\hline Activation function $-\varphi$ & $\begin{array}{c}\text { Symmetric } \\
\text { sigmoidal }\end{array}$ & $\begin{array}{c}\text { Symmetric } \\
\text { sigmoidal }\end{array}$ & Linear \\
\hline Time delays & 7 & 3 & 2 \\
\hline Parameter $-\gamma$ & 2,0 & 2,0 & - \\
\hline Parameter $-\mathrm{a}$ & 2,0 & 2,0 & - \\
\hline Parameter - c & $-1,0$ & $-1,0$ & - \\
\hline No input-output training pairs & \multicolumn{3}{|c|}{80.000} \\
\hline No of iterations & \multicolumn{3}{|c|}{1633} \\
\hline Error & \multicolumn{3}{|c|}{$0,08 \mathrm{E}-6$} \\
\hline Learning coefficient $-\eta$ & $\eta, 9$ \\
\hline Momentum $-\alpha$ & \multicolumn{3}{|c|}{} \\
\hline
\end{tabular}

TABLE II

GRID-SIDE CONTROLLER NEURAL NETWORK ARCHITECTURE

\begin{tabular}{|l|c|c|c|}
\hline & $\begin{array}{c}\text { 1st Hidden } \\
\text { Layer }\end{array}$ & $\begin{array}{c}\text { 2nd Hidden } \\
\text { Layer }\end{array}$ & $\begin{array}{c}\text { Output } \\
\text { Layer }\end{array}$ \\
\hline No of inputs & \multicolumn{3}{|c|}{7 inputs } \\
\hline No of neurons & 18 & 8 & 2 \\
\hline Activation function - $\varphi$ & $\begin{array}{c}\text { Symmetric } \\
\text { sigmoidal }\end{array}$ & $\begin{array}{c}\text { Symmetric } \\
\text { sigmoidal }\end{array}$ & Linear \\
\hline Time delays & 7 & 3 & 2 \\
\hline Parameter - $\gamma$ & 2,0 & 2,0 & - \\
\hline Parameter - a & 2,0 & 2,0 & - \\
\hline Parameter - c & $-1,0$ & $-1,0$ & - \\
\hline No input-output training pairs & \multicolumn{3}{|c|}{80.000} \\
\hline No of iterations & \multicolumn{3}{|c|}{$<9,99 \mathrm{E}-6$} \\
\hline Error & \multicolumn{3}{|l}{0,05} \\
\hline Learning coefficient $-\eta$ & $\eta$ & 0,9 \\
\hline Momentum - $\alpha$ & \multicolumn{3}{|l}{} \\
\hline
\end{tabular}

1 - below the synchronism speed, where active power is supplied to the rotor of the machine; 2- in a zone near the synchronism speed, where the active power flow in the rotor of the machine is practically zero and 3 - in a zone above the synchronism speed, where the machine supplies active power to the grid through the stator and the rotor.

\section{RESULTS}

\section{A. Reactive Power Control}

In this simulation it is intended to vary the value of the reactive power in two steps, a first positive one of $0.2 \mathrm{pu}$, and the other, negative, of 0.4 pu. Fig. 3 and 4 show the signals of the reference voltages generated by the current regulators for the controllers of the grid-side and the rotor-side converters with NN (in the blue colour) and PIs (in the green colour) while Fig. 5 shows the active and reactive power flow.

It can be verified that the behaviour of the system with the $\mathrm{NN}$ is identical to the system with PI controllers.

The response of the $\mathrm{NN}$, face to the response of PIs controllers presents, generally, transients of lower amplitude, faster response and no difference in steady state.
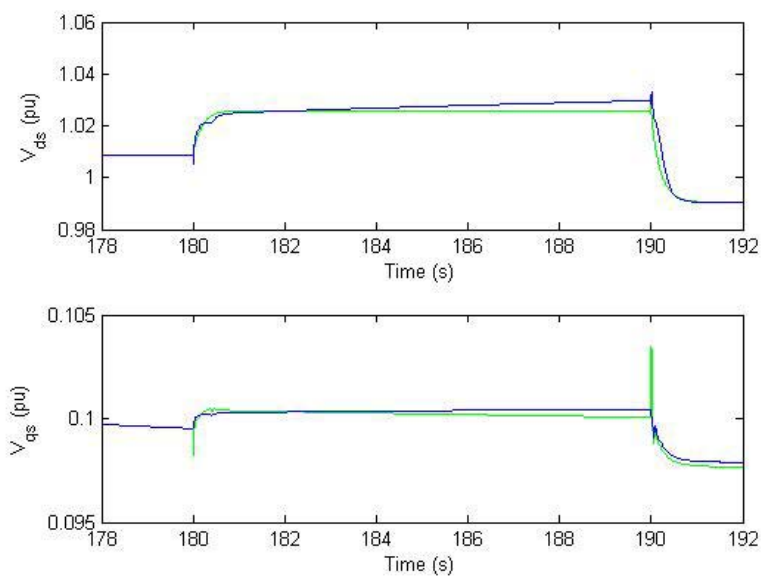

Fig. 3. Reference grid-side voltages $v_{d q}$, due to a step change in the reactive power.
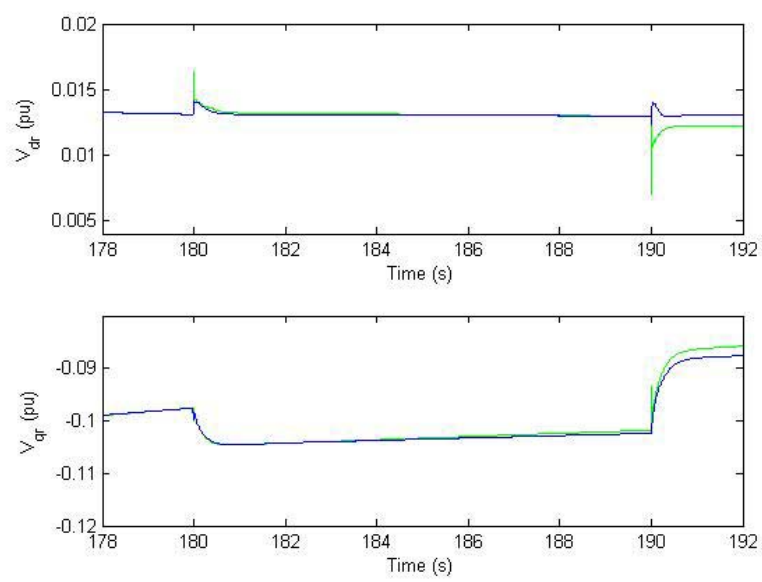

Fig. 4. Reference rotor-side voltage $v_{d q}$, due to a step change in the reactive power.
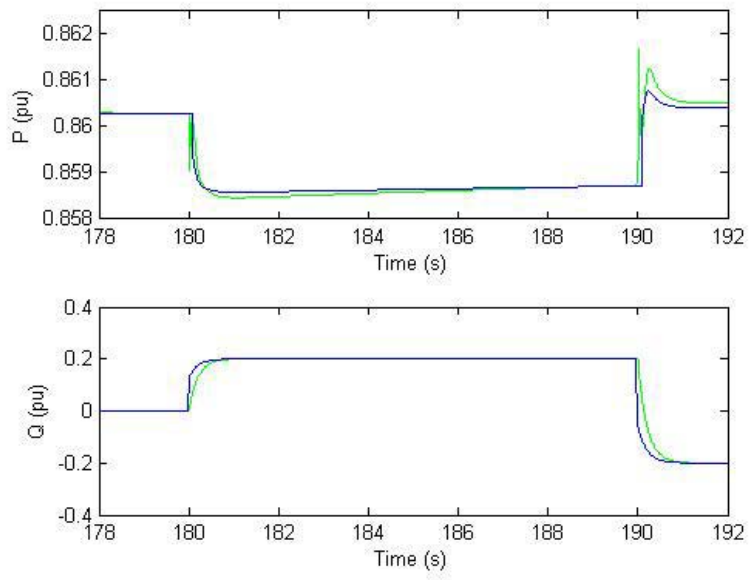

Fig. 5. Active power and reactive power, due to a reactive power change.

The three figures show that the direct component of the reference voltage has a significant level to the control of the reactive power of the grid-side controller, having the remaining units very low levels, of the order of hundredth of pu. 
It can be verified that the response with the $\mathrm{NN}$ is more desirable, not only because in the transition the signal peak is lower in the active power and it does not have a peak in the reactive power, but also for having a faster response to reach the stationary point, namely the value of the active power after 190 seconds.

\section{B. Active Power Control}

In a second test it is intended to verify the response of the system generator/converter due a variation of the active power flow. This variation consisted in applying a negative pulse of amplitude equal to $0.2 \mathrm{pu}$. The reference voltage signals for the controllers of the grid-side and rotor-side converters are registered in Fig. 6 and 7. Fig. 8 shows the active power and reactive power flow.

Also in this condition, the maximum error verified between the two types of control is less than $0.5 \%$, as in the previous case. The responses of the NN controllers present, generally, lower transient amplitudes and faster evolution to steady state. This behaviour is also verified in the main electrical and mechanical variables, where it is verified faster responses and lower transient effects.
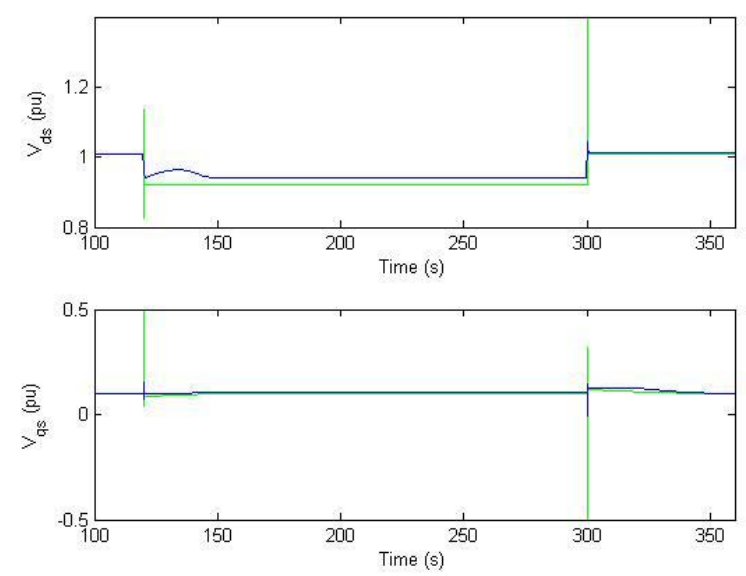

Fig. 6. Reference grid-side voltages $v_{d q}$, due to a step change in the active power flow.
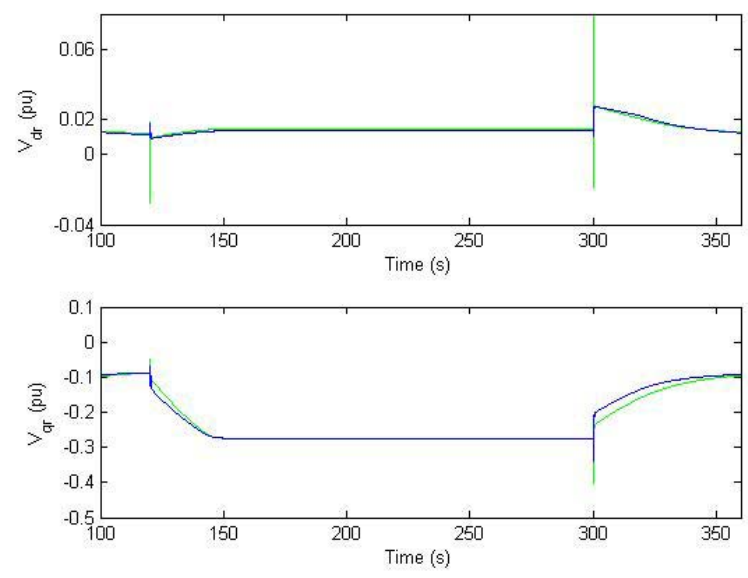

Fig. 7. Reference rotor-side voltages $v_{d q}$, due to a step change in the active power flow.
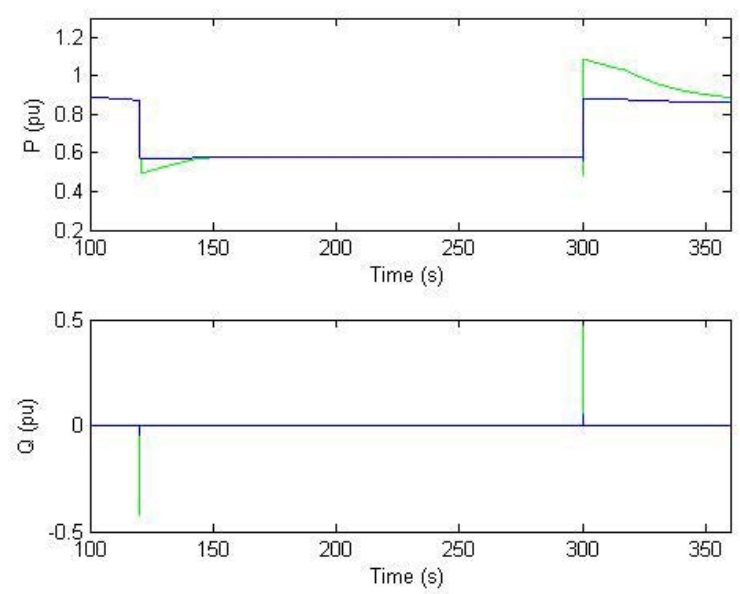

Fig. 8. Active power and reactive power, due to a step change in the active power flow.

\section{Phase-to-Earth Fault}

The following simulation is a phase-to-earth fault in a line of the electrical network located near the wind park occurred at the instant time $t=180 \mathrm{~s}$ and with duration of $\Delta t=180 \mathrm{~ms}$. The fault impedance is about $1 \mathrm{~m} \Omega$. Thus, Fig. 9 and 10 show again the signals of the reference voltages used to control the stator-side and rotor-side converters, respectively, with NNs (in the blue colour) and PIs (in the green colour).

During the fault period, it was verified that the NNs response presents better results than the system that uses PI controllers: beside the peaks already related previously in the transitions, it presents a lower oscillation. It is important to notice that in the direct component of the stator voltage with PI controllers the peaks can reach about $1.7 \mathrm{pu}$ and that can cause some unwanted effects in the electronic devices used in the converters.

In Fig. 11 it can be verified that the disturbances caused in the active power and reactive power delivered to the grid are smoother with the use of the ANNs.

During such fault it can be noticed the reduction in the active power due to a phase loss.
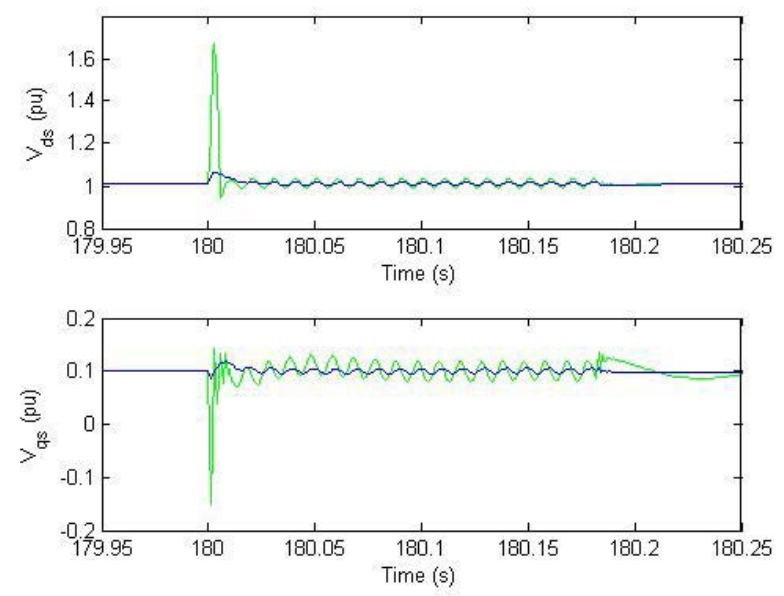

Fig. 9. Reference grid-side voltage $v_{d q}$, due a phase-to-earth fault. 

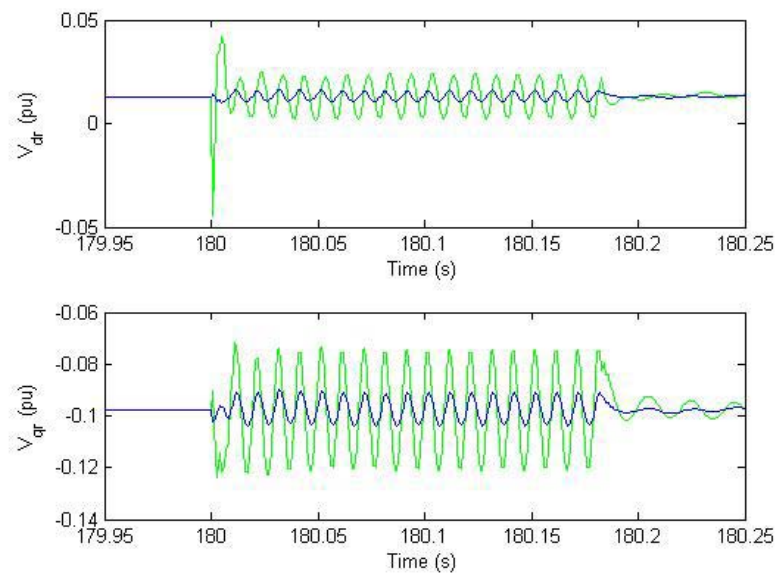

Fig. 10. Reference rotor-side voltage $v_{d q}$, due a phase-to-earth fault.
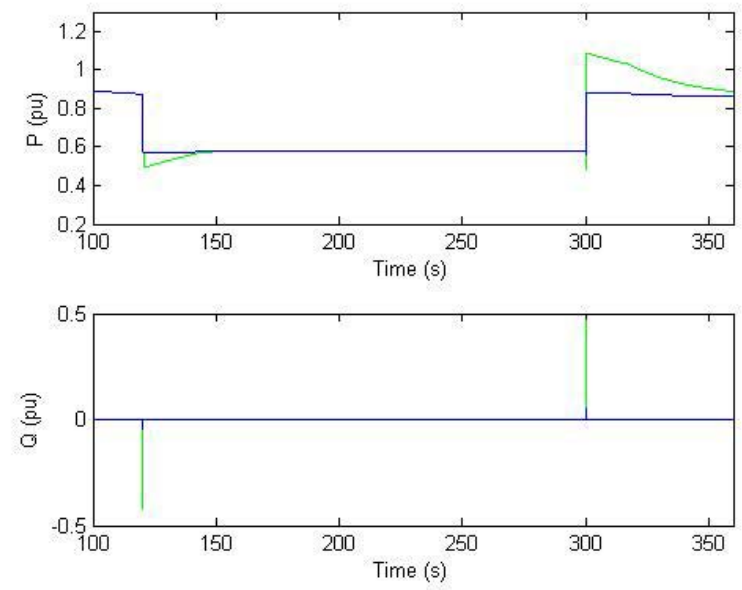

Fig. 11. Active and reactive power, due a phase-to-earth fault.

\section{CONCLUSIONS}

The structures of the proposed neural networks had been trained as a part of the vector control system to estimate the grid-side and rotor-side reference currents (voltages). For a good performance of the NNs it is necessary to carefully train the neural network; the training must contemplate as many operation conditions as possible.

The control system based on NNs that estimate the control parameters of the generator have good characteristics, as it was verified in the presented results.

Comparisons between the traditional systems with PI controllers and the systems with NNs showed some differences in the voltage of the controllers' responses in the systems that used neural networks. It can be noticed the following positive and advantageous aspects: transient regimes present small peaks, or absence of them in same cases, what corresponds to less severe transitions; faster system responses, this is, the system reaches to the steady state condition in shorter time.

Thus, it was demonstrated that the control voltages and currents of the grid-side and rotor-side converters of the DFIG can be obtained using NN based controllers, showing that these can substitute most of the control system blocks and with the designated advantages.

\section{REFERENCES}

[1] T. Ackermann, Wind Power in Power Systems, John Wiley \& Sons, Ltd, England, 2005, ISBN 0-470-85508-8.

[2] A. Tapia, G. Tapia, X. Ostolaza , E. Fernández, J. R. Saenz, "Modeling and dynamic regulation of a wind farm", IEEE International Power Electronics Congress CIEP 2000, pp. 293-297, Acapulco, Mexico, 2000.

[3] A. Tapia, G. Tapia, J. X. Ostolaza, J. R. Saenz, R. Criado, J. L. Berasategui, "Reactive power control of a wind farm made up with doubly fed induction generators (I)", IEEE Porto Power Tech Conference, 2001.

[4] A. Tapia, G. Tapia, J. X. Ostolaza, J. R. Saenz, R. Criado, J. L. Berasategui, "Reactive power control of a wind farm made up with doubly fed induction generators (II)", IEEE Porto Power Tech Conference, 2001

[5] S. Haykin, Neural Networks, 2nd Edition, Prentice Hall, 1999, ISBN 013-273350.

[6] M. G. Simões, B. K. Bose, "Neural network based estimation of feedback signals for vector controlled induction motor drives", IEEE Transactions on Industry Applications, vol. 31, no 3, pp. 620-629, MayJune 1995.

[7] R. Chedid, F. Mrad, M. Basma, "Intelligent control of a class of wind turbine conversion systems", IEEE Transactions on Energy Conversion, vol. 4, pp. 1597-1604, 1999

[8] J. L. Rodríguez-Amenedo, S. Arnalte, J. C. Burgos, "Automatic generation control of a wind farm with variable speed wind turbines", IEEE Transactions on Energy Conversion, vol. 17, no 2, pp. 279-284, 2002.

[9] J. F. Walker, N. Jenkins, Wind Energy Technology, John Wiley \& Sons, Ltd, 1997.

[10] P. Sørensen, A. Hansen, L. Janosi, J. Bech, B. Bak-Jensen, "Simulation of interaction between wind farm and power systems", Risø National Laboratory Report, Roskilde, Risø-R-1281, 2001

[11] A. E. Fitzgerald, J. R. C. Kingsley, Electric Machinery, McGraw-Hill Book Company Inc, 2nd Edition, 1961.

[12] C. Ong, Dynamic Simulation of Electrical Machinery, Prentice Hall, 1998, ISBN: 0-13-723-785-5.

[13] P. T. Krein, J. Bentsman, R. M. Bass, B. L. Lesieutre, "On the use of averaging for the analysis of power electronic systems." IEEE Transactions on Power Electronics, vol. 5, no 2, pp. 182-190, 1990.

[14] J. G. Slootweg, H. Polinder, W. L. Kling, "Initialization of wind turbine models in power system dynamic simulations", IEEE Porto Power Tech Conference, 2001.

[15] J. G. Slootweg, H. Polinder, W.L. Kling, "Dynamic modeling of a wind turbine with direct drive synchronous generator and back to back voltage source converter and its controls", European Wind Energy Conference and Exhibition, Copenhagen, Denmark, July, 2001.

[16] R. Pena, J. C. Clare, G. M. Asher, "Doubly fed induction generator using back-to-back PWM converters and its application to variable-speed wind-energy generation", IEE Proc.-Elect. Power Appl., vol. 143, No 3, May 1996.

[17] H. Demuth, M. Beale, Neural Network Toolbox for use with MATLAB, User's Guide, MathWorks, Inc., 1992. 